\title{
Geoconservação e geodiversidade na área de proteção ambiental da Bica do Ipu - Ceará: desafios para a sustentabilidade
}

\author{
Geoconservation and geodiversity in the environmental protection area of the Ipu - Ceará: \\ challenges for sustainability
}

\author{
LOPES $^{1}$, F. L. S.; CLAUDINO SALES ${ }^{2}$, V. C. \\ marageografia@yahoo.com.br
}

\begin{abstract}
Resumo
Este artigo tem como objetivo apresentar uma análise sobre geodiversidade e geoconservação na Área de Proteção Ambiental da Bica do Ipu- Ceará. A metodologia envolveu levantamento bibliográfico, pesquisa in locu e produção cartográfica. Observa-se que, de maneira geral a geodiversidade na área é representada por uma variedade de paisagens, rochas, minerais, fósseis e solos, os quais constituem a base da vida na Terra. Para fundamentar a análise da área foi possível identificar seu principal curso d'água, o Riacho Ipuçaba, que disseca as rochas sedimentares (arenitos) da Formação Jaicós, Formação Ipu e Formação Tianguá, de idade paleozoica. Como valores da geodiversidade foram identificados o econômico, o cultural, o funcional, o educativo e o científico. Por conta do valor econômico, muitas são as ameaças à geodiversidade, onde a sociedade é o principal agente modificador e degradador. As ameaças consistem em desmatamento, queimadas, retirada/desvio da água de seu curso da água.
\end{abstract}

Palavras-chave: Geodiversidade; geoconservação; APA do Ipu.

\begin{abstract}
This article aims to present an analysis on geodiversity and geoconservation in the Environmental Protection Area of Bica do Ipu-Ceará. The methodology involved bibliographical research, in situ research and cartographic production. It is observed that in general geodiversity in the area is represented by a variety of landscapes, rocks, minerals, fossils and soils, which form the basis of life on Earth. In order to support the analysis of the area it was possible to identify its main watercourse, Riacho Ipuçaba, which dissects the sedimentary rocks (sandstones) of the Formation Ipu, Formation Jaicos and Formation Tianguá, of paleozoic age. As geodiversity values were identified the economic, the cultural, the functional, the educational and the scientific. Because of the economic value, many are the threats to geodiversity, where society is the main modifying and degrading agent. Threats consist of deforestation, burnt out, water withdrawal / diversion from the water course.
\end{abstract}

Keywords: Geodiversity; geoconservation; APA of the Ipu.

\section{INTRODUÇÃO}

O objetivo deste artigo é apresentar as bases de descrição e análise da APA - Área de Proteção Ambiental da Bica do Ipu, unidade de conservação de uso sustentável (Figura 1), sob os aspectos de geodiversidade. A geodiversidade de maneira genérica, representa os processos ligados ao passado geológico responsáveis pela formação de minerais, rochas e fósseis, e também os que ocorrem atualmente. 


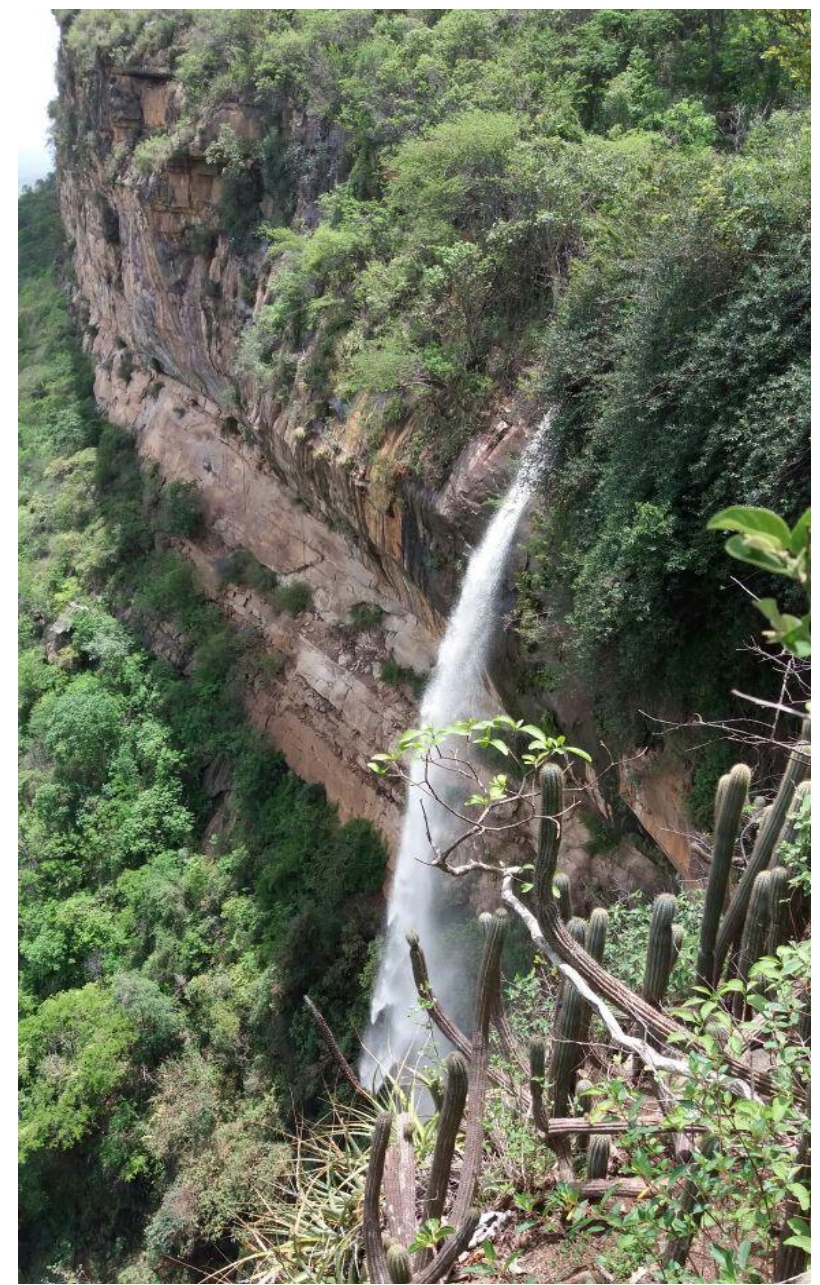

Figura 1: Bica do Ipu. Fonte: Autora (2017)

A Área de Proteção Ambiental da Bica do Ipu (Figura 2), criada por meio do Decreto ${ }^{\circ}$ 25.354, de 26 de janeiro de 1999, abrange uma área de 3.484,66 hectares e localiza-se no município de Ipu-CE, no Planalto da Ibiapaba, situado na porção noroeste do estado do Ceará. Limita-se com os municípios de Pires Ferreira, Croatá, Ipueiras, Guaraciaba do Norte, Reriutaba e Hidrolândia. Compreende uma área irregular de $403 \mathrm{~km}^{2}$. O acesso ao município se dá, partindo de Fortaleza, pela BR 222 e a seguir pela Rodovia CE 187. 


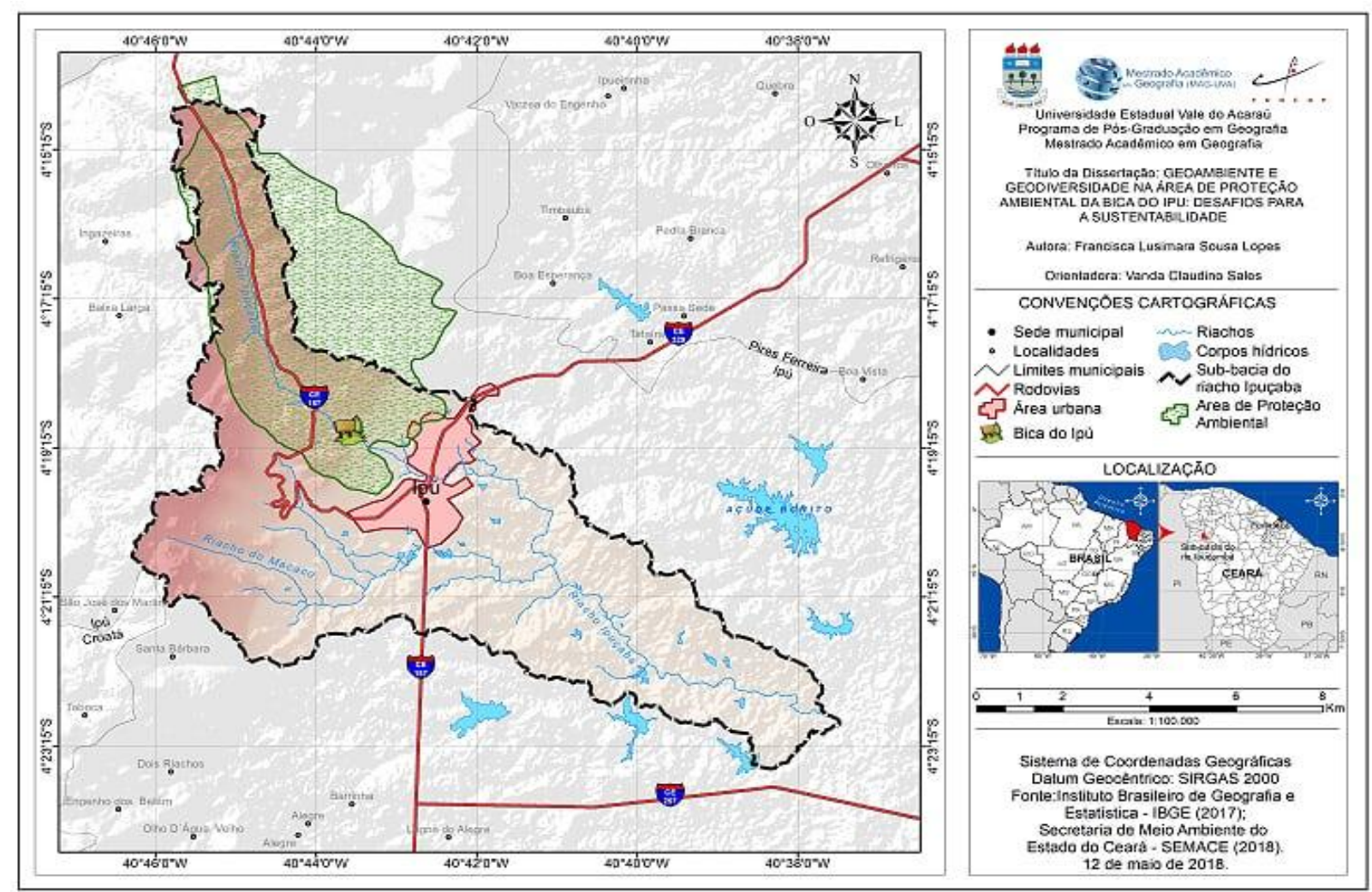

Figura 2: Localização da APA da Bica do Ipu e adjacências. Fonte: Autora (2018)

A população do Ipu e de municípios vizinhos há muito tempo utiliza a bica como área de lazer e contemplação, transformando-a em um ambiente turístico local, sobretudo no período chuvoso. Os habitantes da cidade se orgulham de existir no seu lugar uma queda d'água de feição natural, que chamam de "véu de noiva". Devido a uma paisagem cênica única, o município atrai turistas e um crescente número de novos moradores no entorno da bica, com a presença de pousadas, bares e restaurantes próximo da queda d'água.

Assim, os 3.484,66 hectares do território definido como Área de Proteção Ambiental e sua diversidade de ecossistemas e de patrimônio natural estão sendo ameaçado devido a estas infraestruturas urbano-turística, além de outras associadas com agricultura e indústria, antes mesmo que sua geodiversidade seja conhecida na totalidade.

De acordo com Liccardo et al. (2008), a geodiversidade apresenta um paralelo com a biodiversidade, pois enquanto esta é constituída por todos os seres vivos do planeta e é consequência da evolução biológica ao longo do tempo, a geodiversidade é formada por todo o arcabouço terrestre que sustenta a vida.

Segundo a CPRM (2006 apud OLIVEIRA, 2016), geodiversidade significa:

O estudo da natureza abiótica (meio físico) construído por uma variedade de ambientes, composição, fenômenos e processos geológicos que dão origens às paisagens, rochas, minerais, águas, fósseis, solos, clima e outros depósitos superficiais que propiciam o desenvolvimento da vida na terra, tendo como valores intrínsecos a cultura, o estético, o econômico, o científico, o educativo e o turístico. 
Assim, pode-se constatar que de acordo com Arruda e Barreto (2015), geodiversidade apresenta a variedade de processos e produtos geológicos que ocorrem na natureza. $\mathrm{O}$ seu estudo serve como base para auxiliar tanto nos projetos científicos na área das geociências, como projeto para planejamento e gestão territorial de uma área geográfica.

Segundo Gray (2004) e Brilha (2005), a geodiversidade apresenta diversos "valores" fundamentais. Os valores da geodiversidade são classificáveis em sete, que sao o intrínseco, cultural, estético, econômico, funcional, científico e educativo.

\section{I - Valor intrínseco:}

De todos os valores atribuidos à geodiversidade, o intrínseco é, provavelmente, o mais subjetivo. Essa subjetividade advém da dificuldade de quantificação deste valor e da sua ligação com as perspectivas filosóficas e religiosas de cada sociedade e cultura. Há quem defenda que a Natureza deve estar à disposição dos seres humanos, a fim de satisfazer as suas necessidades, colocando assim o Homem em um nível superior aos dos restantes dos seres vivos deste planeta. Outros há que, pelo contrário, consideram que o Homem é parte integrante da Natureza, fazendo com que esta possua um valor próprio. Como é óbvio, não se pretende dar aqui nenhuma resposta concreta a esta questão, apenas suscitar a reflexão e sugerir aos leitores interessados a consulta de bibliografia variada relacionada com estas e outras questões no âmbito da filosofia ambiental. Desta forma, a geodiversidade terá um valor intrínseco independentemente da sua maior ou menor valia para o Homem.

\section{II - Valor Cultural:}

O valor cultural é conferido pelo Homem quando se reconhece uma forte interdependência entre seu desenvolvimento social, cultural e/ou religioso e o meio físico que o rodeia. Quando um determinado aspecto geológico é explicado pela população com base em justificações transcendentais, Gray (2004) sugere a utilização do termo geomitologia. Bastante próximo da geomitologia podemos considerar aspectos folclórico, como associação de aspectos particulares da paisagem com imagens conhecidas, questões arqueológicas e históricas. A construção de estruturas defensivas em locais geomorfologicamente favoráveis é um claro exemplo do valor histórico que alguns locais apresentam.

Podem ainda referir-se outros aspectos culturais que surgiram na dependência das características geológicas locais. Material para construção (uso de argilas, cerâmicas e rochas da região), também exemplifica a relação que se pode estabelecer entre a geodiversidade e a cultura tradicional. Outro exemplo são a gastronomia e vinhos, dada a conjugação de elementos 
particulares da geodiversidade que agregam. E por último pode-se considerar ainda como valor cultural o uso de uma dada particularidade e/ou fenômeno geológico como "imagem de marca" de uma região ou localidade. Como exemplo, tem-se a ocorrência de fósseis.

\section{III - Valor estético:}

A atribuição de um valor estético à geodiversidade é também uma atitude subjetiva e não passível de quantificação. Enquanto que, para a maior parte das pessoas, a observação de paisagens naturais constitui uma atividade de lazer bastante consensual, já decidir sobre se uma paisagem é mais bela do que outra é algo inevitavelmente discutível. No entanto, é inegável que todas as paisagens naturais possuem algum tipo de valor estético. Grande parte do deslumbramento do público pelo contato com a natureza está associada a aspectos geológicos e geomorfológicos.

Nesse tocante, cita-se a crescente busca de locais onde é possível a observação de paisagens. Coloca-se aqui o crescente número de praticantes de atividades de lazer (caminhadas, escaladas...) em zonas naturais, fato bem demonstrativo do valor acrescentado que os meios naturais apresentam. O valor estético da geodiversidade tem sido muito usado também na produção artística. Assim é que existem artistas que se inspiraram na geodiversidade, para criar obras de artes que fazem parte do patrimônio cultural da humanidade.

IV - Valor econômico:

Este reconhecimento do valor econômico da geodiversidade é algo mais objetivo e compreensível. Estamos habituados a atribuir um valor econômico a praticamente todos os bens e serviços, pelo que compreendemos facilmente que as rochas, os minerais, os fósseis tenham também o seu valor econômico. Exemplo é a dependência da geodiversidade em termos energéticos: a exploração de petróleo, carvão e gás natural são essenciais quer para a produção de combustíveis, quer para a produção de diversas formas de energias; a exploração de minerais radioativos, como os de urânio, que são usados como combustível de centrais nucleares um pouco por todo o mundo; o aproveitamento do calor interno da Terra (energia geotérmica), também utilizada na produção de outros tipos de energia; construção de barragens para aproveitamento de hidroelétrica em locais onde a geomorfologia e a geologia apresentam as condições necessárias para este tipo de infraestrutura, entre outros. Assim, é difícil termos um bem ou produto que não tenha necessitado, em alguma fase da sua produção, de matérias geológicos essenciais em todas as obras de construção civil, como areia, granito, argila.

Outro fator importante da geodiversidade são as águas subterrâneas, que adquirem uma relevância econômica crescente. E por fim, uma forma de interesse econômico para a 
geodiversidade é a utilização de gemas (safiras, rubis, diamantes) e fósseis em joalharia, e o comércio, algumas vezes ilegal de amostras raras de minerais e fósseis para colecionismo privado, com valores elevados.

V - Valor funcional:

Gray (2004) introduziu o conceito, reconhecendo que se trata de uma ideia normalmente não aplicável à conservação da natureza. Pode ser encarada sob dois aspectos.

1) Valor da geodiversidade in situ, de caráter utilitário do homem;

2) $\mathrm{O}$ valor da geodiversidade enquanto substrato para a sustentação dos sistemas físicos e geológicos na superfície terrestre. O valor utilitário da geodiversidade in situ refere-se a valorização da geodiversidade que se mantém no local de origem, ao contrário do econômico da geodiversidade depois de explorada, abordado anteriormente. Exemplo de caráter utilitário refere-se ao papel da geodiversidade no suporte para a realização das mais variadas atividades humanas (construção de vias de comunicação, barragens e cidades) ou no armazenamento de certas substâncias como o carbono, em solos, a água subterrânea, em aquíferos, resíduos, em aterros e o papel do solo na agricultura e na produção florestal.

Gray (2004) tanbém considerou o caráter utilitário da geodiversidade como suporte para a realização das mais variadas atividades humanas, como o papel do solo na agricultura e na produção florestal.

\section{VI - Valor Científico e Educativo:}

A geodiversidade apresenta um valor científico e educativo inegável. A investigação científica, no domínio das Ciências da Terra, baseia-se no acesso e posterior estudo de amostras representativas da geodiversidade. A investigação fundamental ajuda-nos a conhecer e interpretar a geodiversidade e a reconstituir a longa história da terra. A investigação de caráter aplicado contribui para melhorar a relação da espécie humana com a geodiversidade, quer ajudando a viver em zonas potenciais de risco (vulcânico, sísmico, elevada declividade...) quer monitorizando ou controlando o impacto sobre o ambiente das nossas agressivas atividades industriais.

VII - Valor educativo:

A educação em Ciências da Terra só pode ter sucesso se permitir o contato direto com a geodiversidade. Quer no que respeita a atividade educativas formais, de âmbito escolar, quer nas atividades educativas não formais, dirigidas ao público em geral, as saídas de campo permitem conferir a geodiversidade um extraordinário valor educativo. Os valores científico e educativo na 
geodiversidade baseiam-se no acesso e posterior estudo de amostras representativas da geodiversidade. Ele pode ocorrer como atividade educativas formais ou informais.

Conhecer os aspectos da geodiversidade é uma primeira etapa no caminho da geoconservação. De maneira ampla o termo geoconservação tem sido usado para descrever atividades relacionadas à proteção do patrimônio geológico e geomorfológico, tendo como ação prioritária a valorização e divulgação dos sítios com valor patrimonial. Por fim, estes conceitos configuram também uma visão holística, de preocupação com o uso consciente dos recursos naturais.

O conceito surge devido a necessidade urgente de se desenvolverem estratégias de conservação da biodiversidade levando em consideração o valor econômico, cultural ou sentimental. Segundo Sharples (2002 apud Nascimento et. al, 2015), a geoconservação tem como objetivo proteger a geodiversidade relacionada aos importantes processos e feições geológica, geomorfológica e de solos, garantindo a manutenção da história da evolução em termo de velocidade e magnitude.

Um marco histórico para a geoconservação foi a criação do primeiro Parque Nacional de Yellowstone, em 1872, nos Estados Unidos. Com ele se iniciou a história das Unidades de Conservação no mundo.

Geoconservação é, ainda, definida como sendo o conjunto de técnicas e medidas que visam assegurar a conservação (inclui a reabilitação) do patrimônio geológico e da geodiversidade, baseada na análise de seus valores intrínsecos, vulnerabilidade e do risco de degradação (CARCAVILLA et al., 2007).

\subsection{Caracterização da área de estudo}

A Serra da Ibiapaba, onde se localiza a Bica do Ipu, se situa geologicamente na borda oriental de uma das mais significativas bacias sedimentares brasileiras, a bacia sedimentar do Parnaíba (PIRES, 2003). A Bacia do Parnaíba tem uma origem que remonta ao Paleozoico médio, mais precisamente, entre os períodos Siluriano e Devoniano (BRITO NEVES, 1999).

Segundo Claudino-Sales (2016), o Planalto da Ibiapaba se sobressai como uma geoforma modelada como um glint, espetacular em relação à baixa superfície da região oeste do Ceará. O relevo glint é caracterizado pelo fato de ser uma feição de bacia sedimentar contendo sopé e/ou vertentes sustentadas por rochas cristalinas, e não sedimentares, como a cuesta. Apresenta front dissecado, mantido sobretudo pelas rochas do grupo sedimentar Serra Grande, integrante da bacia sedimentar do Parnaíba. O glint tem partes da vertente bem como a depressão periférica sustentadas por rochas de embasamento cristalino pré-cambriano, incluindo granitos. 
A Bica do Ipu tem uma altura de aproximadamente $130 \mathrm{~m}$ e é formada a partir da precipitação das águas do Riacho Ipuçaba, o qual drena uma extensão de $10 \mathrm{~km}$ desde as nascentes até o local da bica (Figura 3). O curso d'água disseca as rochas sedimentares (arenitos) da Formação Jaicós, Formação Tianguá e Formação Ipu, integrantes do Grupo Serra Grande, o qual caracteriza as camadas basais da Bacia do Parnaíba.

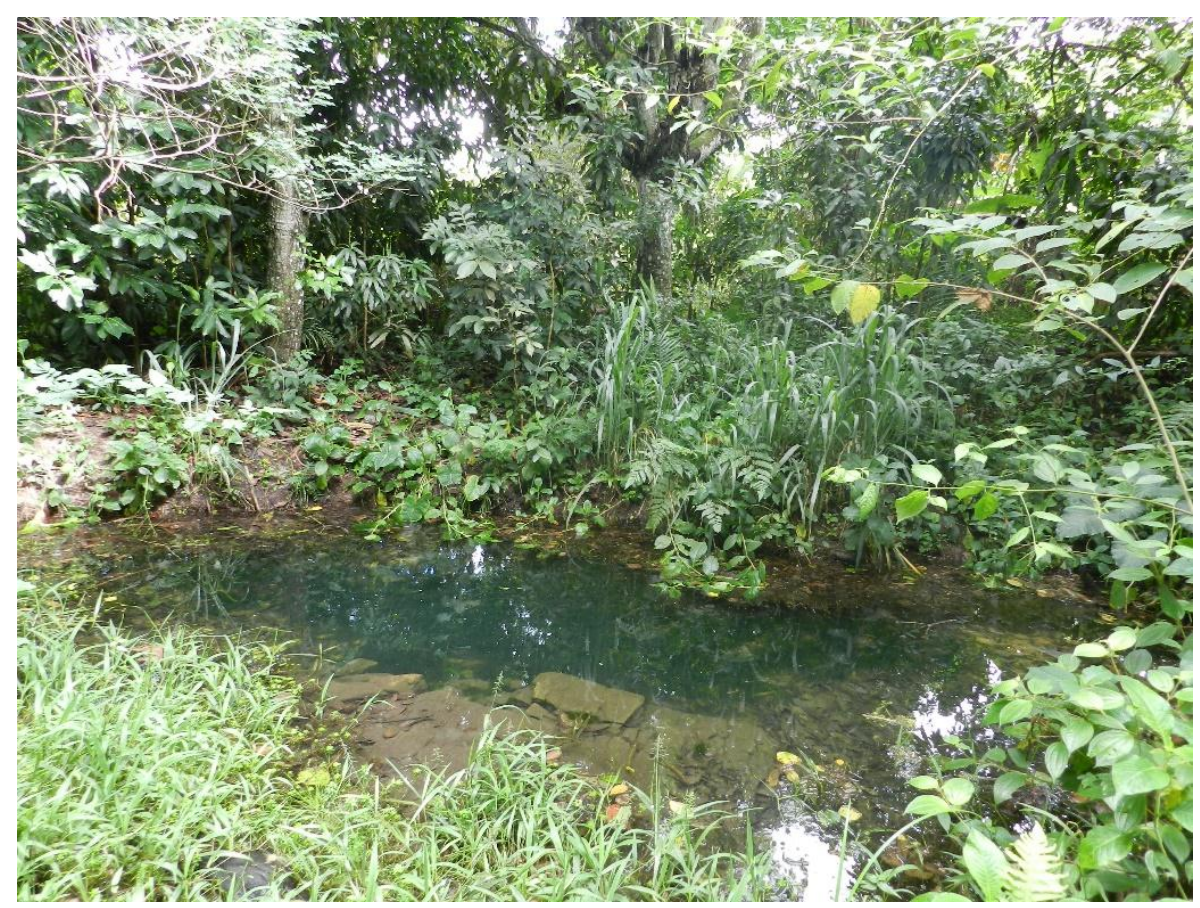

Figura 3: Nascente do Riacho Ipuçaba. Fonte: Arquivo da APA da Bica do Ipu (2017)

A maior parte do município de Ipu estende-se ao longo do vale do Riacho Ipuçaba, afluente do Rio Jatobá, que é o maior tributário do Rio Acaraú, o segundo maior rio do Estado do Ceará. O Ipuçaba nasce nas escarpas da Ibiapaba e forma um rico e fértil vale, cheio de grandes canaviais (MELLO, 1985).

O Riacho Ipuçaba nasce nas proximidades do front do glint, mas não escoa na direção do mergulho das camadas - ao contrário, ele escoa em direção ao Estado do Ceará, criando nesse sentido um vale do tipo anaclinal, que drena contrariamente à inclinação dos estratos sedimentares. Ao interceptar o front do glint, o Riacho Ipuçaba propicia o fenômeno da queda d'água, criando um ambiente de extrema beleza cênica que se diferencia do restante da paisagem dos arredores.

O município situa-se em posição de destaque, como elo entre o Sertão Central e a Serra da Ibiapaba. Apresenta $25 \%$ de seu território em área serrana, no qual a vegetação adensada e o clima ameno produzem um ambiente de serra úmida. A proximidade com a serra ameniza o clima do território situado na planície e as estiagens, embora faça parte do chamado "Polígono das Secas". 
$\mathrm{Na}$ área de estudo as formas de relevo, a leste, são suaves e pouco dissecadas fazendo parte da superfície de aplainamento Sertaneja. A oeste estabelece-se o planalto cuestiforme, glint da Ibiapaba, com altitudes próximas dos 500 metros (figura 4).

Informações do Atlas do Ceará (CEARÁ-IPLANCE, 1997) e do Plano Estadual de Recursos Hídricos (SRH-CE, 1992) indicam que o clima regional apresenta uma variação de temperatura, em valores médios, entre mínimas de $19^{\circ} \mathrm{C}$ e máximas de $29^{\circ} \mathrm{C}$, e precipitação pluviométrica média anual oscilando em torno de $1.100 \mathrm{~mm}$.

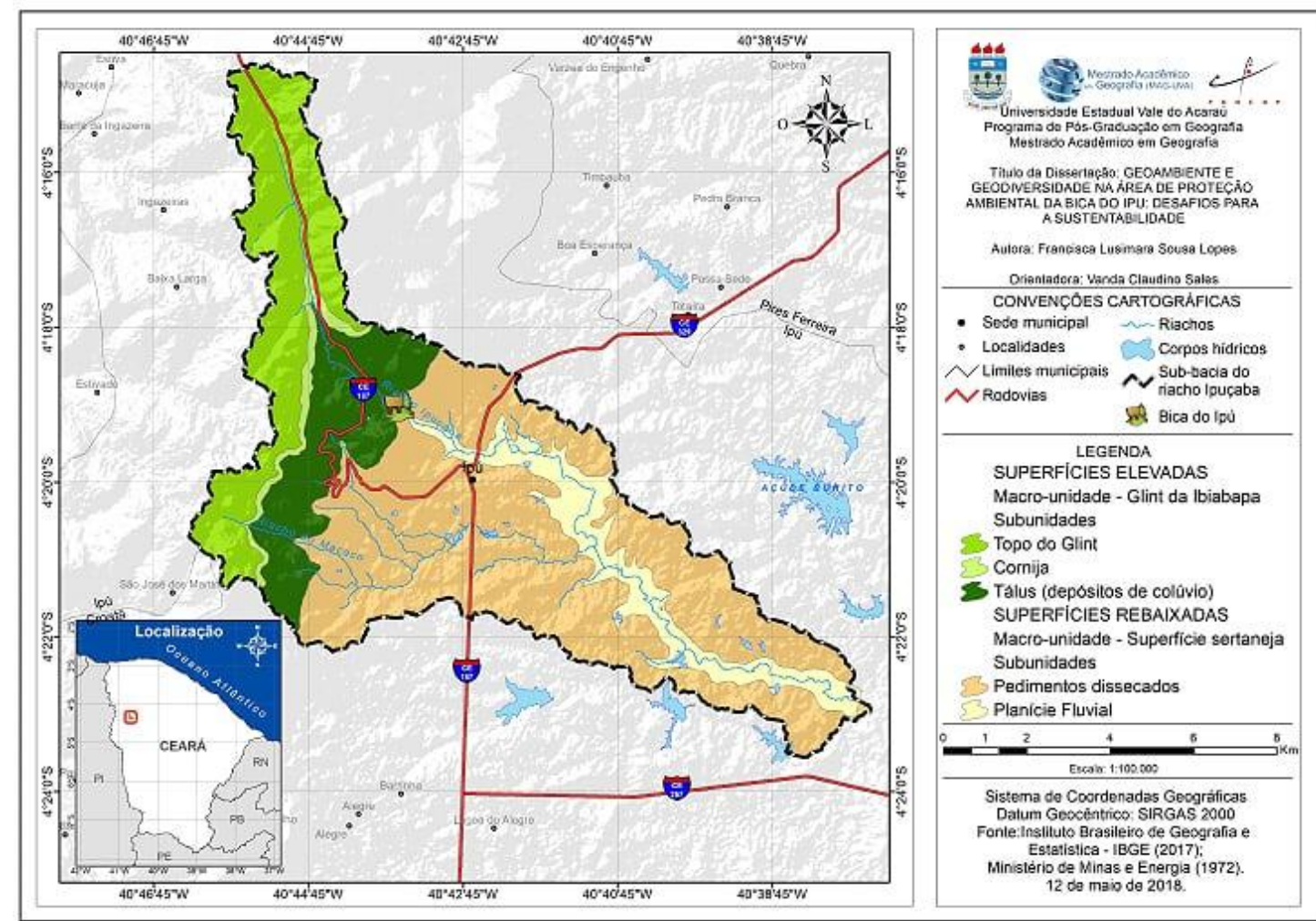

Figura 4: Geomorfologia da APA de Proteção Ambiental Bica do Ipu e adjacências. Fonte: Autora (2018)

Verifica-se que parte do município de Ipu está no domínio geológico-ambiental do complexo granitóide deformado (granitóide Santa Quitéria, do Complexo Tamboril Santa-Quitéria, de idade neoproterozóica), na unidade geomorfológica "superfície de aplainamento Sertaneja". Os outros domínios geológicos são caracterizados pela ocorrência de depósitos coluvionares, os quais dominam na área de maior urbanização. .No extremo oeste do município, ocorrem os materiais sedimentares correspondentes à Formação Ipu (conglomerados polimictos com matriz feldspática areno-argilosa, com seixos de quartzo, ardósia, quartzito e arenito; arenitos grossos, de cor cinza, mal selecionados, apresentando estratificação cruzada acanalada de grande porte), Formação Tianguá (folhelhos cinza-escuros, bioturbados, sideríticos e carbonáticos, de arenitos cinza-claro, fino e médio, feldspáticos e intercalados com siltitos) e Formação Jaicós (arenitos cinzas, grossos, 
contendo seixos angulares a subangulares, mal selecionados e friáveis, com estratificações acanaladas e retas de médio e a grande) (SILVA, 2014) (Figura 5).

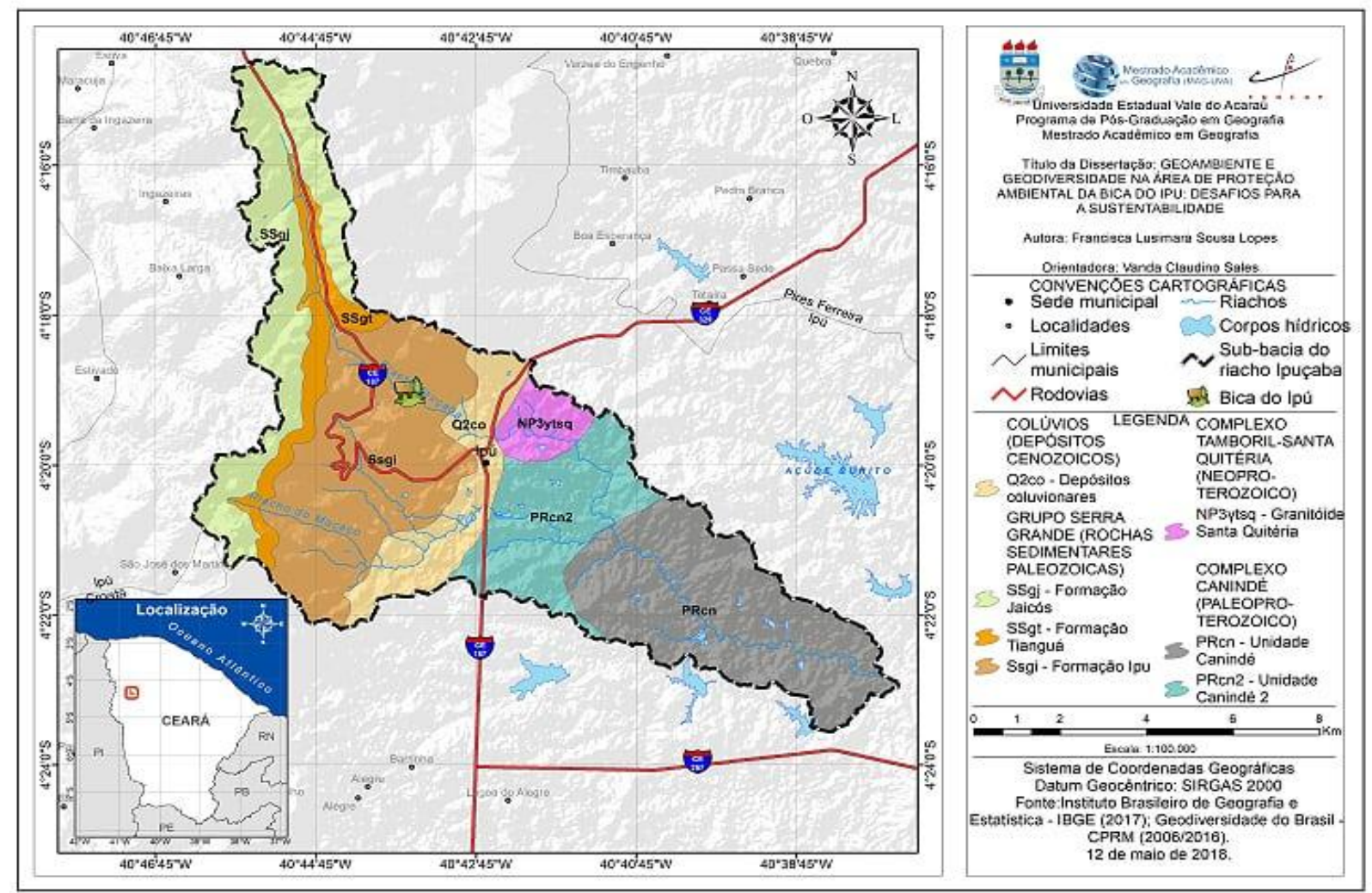

Figura 5: Geologia da Área de Proteção Ambiental da Bica do Ipu e Adjacências. Fonte: Autora (2018)

No município de Ipu pode-se distinguir três domínios hidrogeológicos distintos: rochas cristalinas (superfície aplainada), sedimentos da Formação Serra Grande (glint da Ibiapaba) e depósitos aluvionares.

As rochas cristalinas na área representam o que é denominado comumente de "aquífero fissural". Como basicamente não existe uma porosidade primária nesse tipo de rocha, a ocorrência da água subterrânea é condicionada por uma porosidade secundária representada por fraturas e fendas, o que se traduz por reservatórios aleatórios, descontínuos e de pequena extensão (CPRM, 2016). Dentro deste contexto, em geral, as vazões produzidas por poços são pequenas e a água, em função da falta de circulação e dos efeitos do clima semiárido é, na maior parte das vezes, salinizada. Essas condições atribuem um potencial hidrogeológico baixo para as rochas cristalinas, sem, no entanto, diminuir sua importância como alternativa de abastecimento em casos de pequenas comunidades ou como reserva estratégica em períodos prolongados de estiagem (BENVENUTI e FEITOSA, 1998)

As formações sedimentares paleozoicas representam, na região, o domínio de mais alto potencial do ponto de vista hidrogeológico. Entretanto, no município de Ipu, em função da ocorrência desses 
sedimentos ficar restrita apenas à porção oeste, abrangendo uma área muito pequena em relação a área total do município, esse domínio decresce em importância.

Os depósitos aluvionares são representados por sedimentos areno-argilosos recentes, que ocorrem margeando as calhas do Riacho Ipuçaba e afluentes que drenam a região. Apresentam, em geral, uma boa alternativa como manancial, tendo uma importância relativa alta do ponto de vista hidrogeológico.

Normalmente a alta permeabilidade dos termos arenosos compensa as pequenas espessuras, produzindo vazões significativas.

Levantamentos realizados indicam para o domínio das rochas cristalinas uma vazão média de $1,7 \mathrm{~m}^{3} / \mathrm{h}$, resultado de uma análise estatística de mais de 3.000 poços no cristalino do estado do Ceará (MÖBUS et al., 1998 apud BENVENUTI e FEITOSA, 1998). Para o domínio das rochas sedimentares foi estimada uma vazão média de $4,5 \mathrm{~m}^{3} / \mathrm{h}$, resultado de uma análise estatística das informações de vazão de 192 poços, obtidas no Plano Estadual de Recursos Hídricos do Estado do Ceará (SRH-CE, 1992).

Ocorrem regionalmente solos dos tipos bruno não-cálcicos, que é um solo típico do sertão nordestino brasileiro, mesmo apresentando a região clima ameno, pois a área conta com estiagem severa em vários meses do ano. Esse tipo de solo apresenta suscetibilidade à erosão relativamente alta, em função da coesão e consistência dura do horizonte A e do forte gradiente textural entre os horizontes A e B (Oliveira et al., 1992). Ocorrem ainda solos podzólicos que têm características de agregação e boa estruturação, apresentam certa suscetibilidade aos processos erosivos, que são tão mais intensos quanto maiores são as descontinuidades texturais e estruturais. Ocorrem ainda latossolos, que são encontrados nas áreas de vegetação de floresta (densa, aberta e mista com palmeira), em relevo que varia de plano a forte ondulado; de modo geral apresentam reduzida suscetibilidade à erosão (Vieira, 1988; Oliveira et al., 1992; Resende et al., 1995). A boa permeabilidade e drenabilidade e a baixa relação textual B/A garantem uma boa resistência desses solos à erosão (Guerra, 2003).

A cobertura vegetal na área é caracterizada pela presença de caatinga arbórea (floresta caducifólia espinhosa), caatinga arbustiva aberta, mata seca (floresta subcaducifólia tropical pluvial) e mata úmida (floresta subperenifólia tropical plúvio-nebular) (Figura 6). A vegetação predominante é a caatinga, embora os registros da diversidade das espécies que ocorram neste bioma venham aumentando nos últimos anos. Assim, é possível que plantas ocorrentes na Mata Atlântica, Cerrado e Amazônia possam ter seu limite de distribuição ampliado para a caatinga (Siqueira Filho et al., 2012). 
De acordo com o último censo do IBG (2010) a população do município de Ipu no início dessa década era de 40.296 habitantes, com uma taxa de urbanização de 65\%, distribuída num território de $629,32 \mathrm{~km}^{2}$.

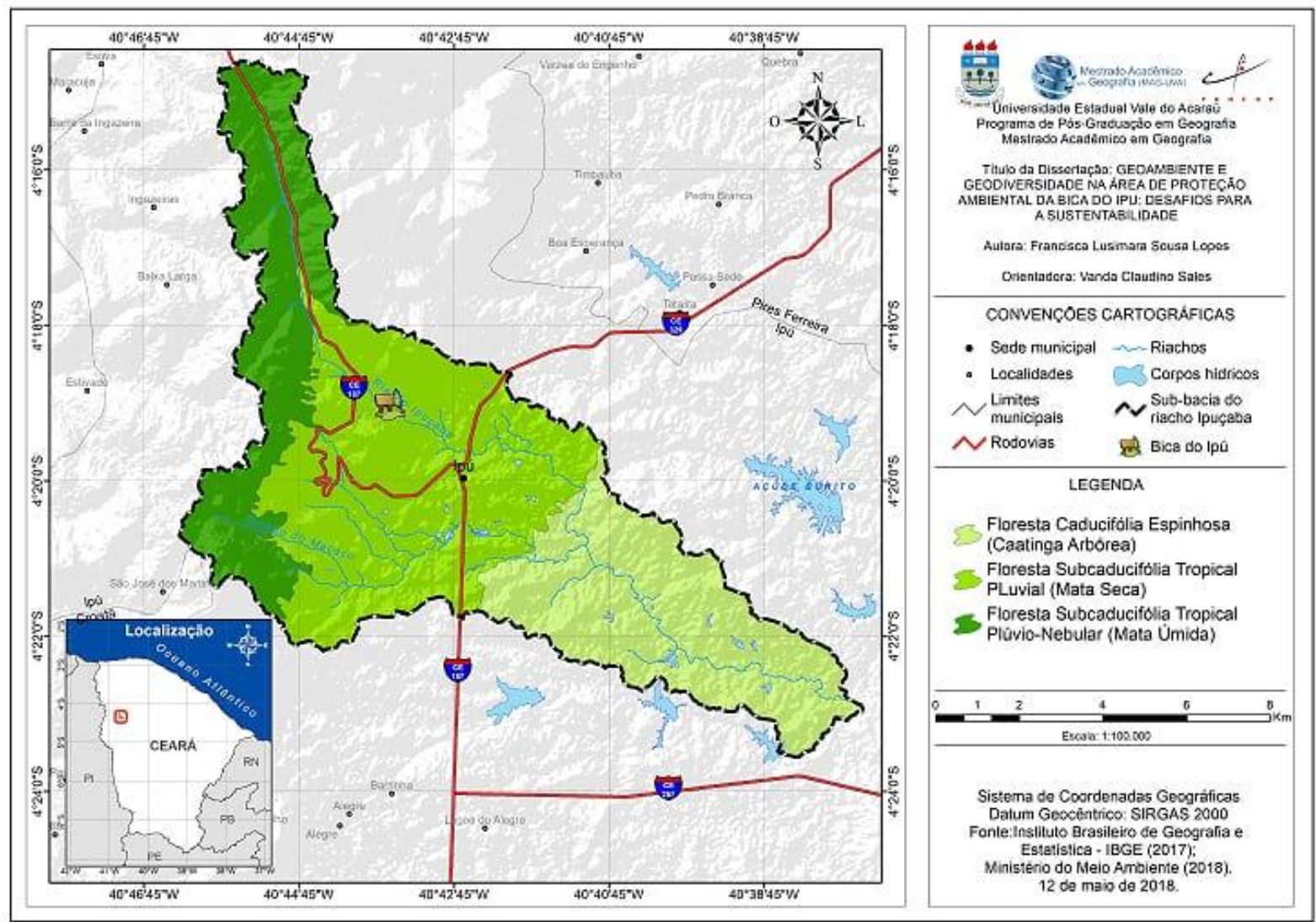

Figura 6: Fitogeografia da Área de Proteção Ambiental da Bica do Ipu e adjacências. Fonte: Autora (2018)

\section{METODOLOGIA}

O presente trabalho resulta de atividades associadas com levantamento bibliográfico e cartográfico, trabalhos de campo e geoprocessamento. A perspectiva foi identificar os principais elementos associados com geodiversidade e geoconservação da área de pesquisa, obter embasamento teórico e realizar a descrição científica da área, produzindo, dessa maneira, um recorte da realidade na área de Proteção Ambiental da Bica do Ipu, uma unidade de conservação de uso sustentável.

Os procedimentos metodológicos realizados na pesquisa foram:

1. levantamento bibliográfico e documental: durante essa etapa de levantamento bibliográfico, foram coletados livros como: Patrimônio Geológico e Geoconservação: a conservação da natureza na sua vertente geológica (Brilha, 2005), Megageomorfologia do Estado do Ceará (Claudino-Sales, 2016), Geomorfologia do Brasil, (Cunha e Guerra, 2003), teses de 
doutorado como: Evolução Geomorfológica da Ibiapaba setentrional, Ceará: Gênese, Modelagem e Conservação (Moura Fé), além do Altas Do IPECE e Mapas da CPRM. Foram ainda pesquisados diversos sites, como os da Universidade Estadual Vale do Acaraú e Secretaria Estadual do Meio Ambiente, dentre outros.

Sobre o levantamento documental, buscou-se artigos tais como Paisagem da Terra da Ibiapaba/Ipu-CE: cartografia literária e visual (Coelho, 2008) e realizou-se pesquisa na Superintendência Estadual do Meio Ambiente- SEMACE.

2. Produção de mapas: usou-se como base cartográfica mapa do Instituto Brasileiro de Geografia e Estatística- IBGE (2017), no qual foram obtidas informações sobre os limites dos municípios, dos riachos, estradas, corpos hídricos, etc. Realizou-se também a elaboração de mapas temáticos, tais como: mapa de localização, tendo como base cartográfica mapa da Secretaria de Meio Ambiente do Estado do Ceará- SEMACE(2018); mapa temático "Geomorfologia”, tendo como base cartográfica mapa do Ministério de Minas e Energia(1972); mapa temático "Geologia", tendo como base cartográfica o mapa da CPRM - Serviços Geológico do Brasil (2016) e por último, mapa temático "Fitogeografia da APA", tendo como base cartográfica mapa do Ministério do Meio Ambiente (2018).

3. Realizações de trabalhos de campo: deve-se destacar que, os termos geodiversidade e geoconservação na APA são poucos conhecidos e divulgados. Os trabalhos de campo foram realizados no sentido de procurar identificar os elementos naturais associados com esses temas, e implicaram em caminhamento e escaladas, do nível rebaixado do município de Ipu até o topo do paredão rochoso no qual o Riacho Ipuçaba forma a Bica do Ipu, em meio a formação vegetal florestal.

\section{RESULTADOS E DISCUSSÃO}

\subsection{O valor da Geodiversidade e Geoconservação na APA da Bica do Ipu}

O primeiro valor a ser atribuído a geodiversidade da APA da Bica do Ipu é o valor artístico. Nesse aspecto, tem-se o romance ambientado no século XVII, retratando seus personagens e tramas indissociáveis do cenário composto pelas paisagens do Ceará. Os caminhos trilhados pelos personagens do romance do escritor José de Alencar - "Iracema - a virgem dos lábios de mel” - tem como pano de fundo Ipu e sua bica. A bica representa o local onde se banhava Iracema. O romance indianista brasileiro concebe a jovem tabajara, Iracema, um mito literário presente no imaginário brasileiro há 151 anos. A visão de natureza, no século XIX por Alencar, é apresentado através da fusão- Iracema/Floresta, a terra "virgem" até então não explorada por estrangeiros. Além do que, a protagonista retrata o espírito harmonioso da floresta que está explícito em alguns fragmentos, tais 
como as indicações "virgem dos lábios de mel', "sorriso mais doce que o favo de jati”, "cabelos mais longos que o talhe de palmeira e mais negros que a asa da graúna", "se banhava na sombra da oiticica e os ramos da acácia silvestre aspergiam flores sobre seus cabelos úmidos", entre outros. Isso está visível na seguinte citação:

Mais rápida que a ema selvagem, a morena virgem corria o sertão e as matas do Ipu (...) Iracema saiu do banho; o alfôjar ainda a roreja (...) Tupã deu a grande nação tabajara toda essa terra. Nós guardamos as serras aonde manam os córregos, com os frescos ipus onde cresce a maniva e o algodão e abandonamos ao bárbaro potiguara, comedor de camarão, as areias nuas do mar, os secos tabuleiros sem água e sem floresta. Agora os pescadores da praia (...) deixam vir pelo mar a raça branca dos guerreiros de fogo, inimigos de Tupã (ALENCAR, 1956, p.13-21).

A descrição acima indica que Ipu, a Bica, as matas do Ipu, a terra, os córregos, a cultura indígena, emanam no romance como representação simbólica-afetiva.

Dentre o valor cultural da geodiversidade, estão fatores originários da forte interdependência entre o desenvolvimento social, cultural e/ou religioso e o meio físico circundante. Pode ser visto na produção artística, em esculturas, utensílios, músicas, poemas e fotografias que abundam na região, retratando a bica.

O valor econômico da geodiversidade é algo objetivo. Dentre muitos exemplos de valorização econômica da geodiversidade neste lugar, cita-se a utilização da água para fins comerciais. É o caso da água mineral da empresa Acácia, para a qual os recursos hídricos locais são essenciais no empreendimento e fabricação. A empresa conta com poços de extração desse recurso no distrito de Várzea do Jiló. O empreendimento utiliza os aspectos literários da área da bica como motivação econômica, divulgando "Iracema" e a bica no seu rótulo (Figura 7). A localização da empresa no município de Ipu, tem como base o domínio das rochas sedimentares que abrange, respectivamente, $74 \%$ das captações de água subterrânea existentes na área.

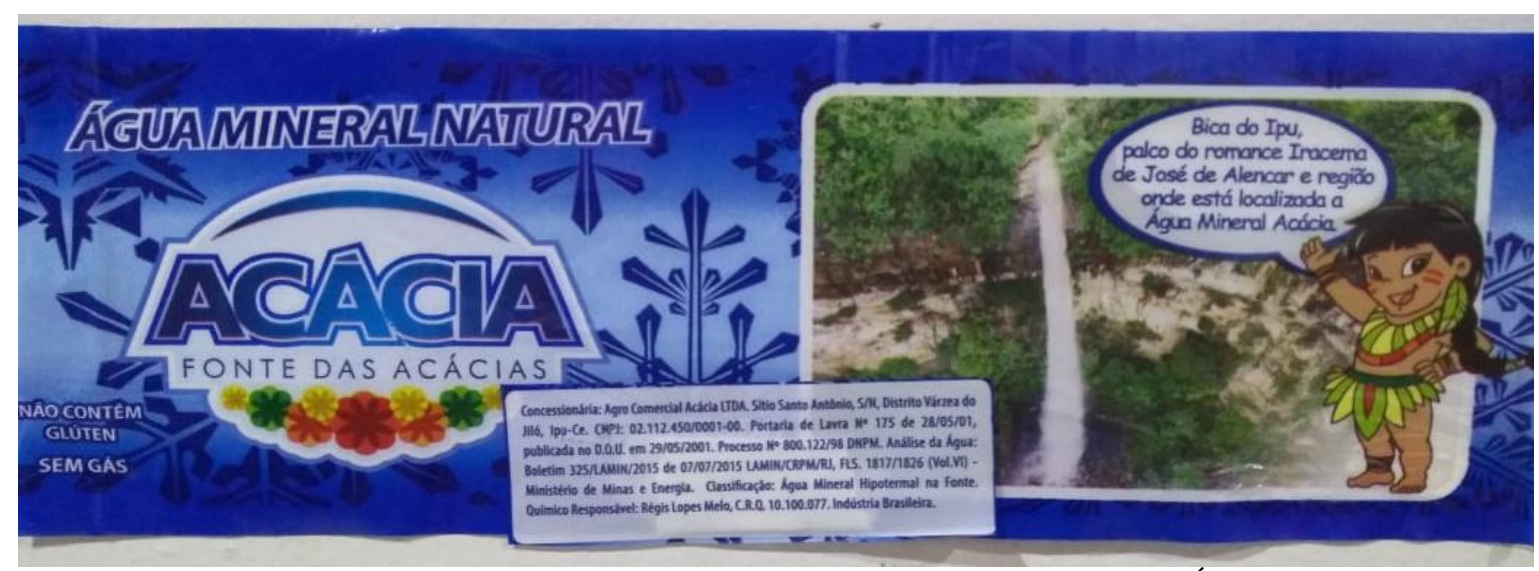

Figura 7: Rótulo do garrafão de 20 litros da Empresa Acácia - Símbolo Índia Iracema 
Cita-se também a instalação de restaurantes privados e pousadas na proximidade da Bica, com concessão da anuência da prefeitura, para atender aos turistas e a população local que usa a bica para o lazer e recreação.

$\mathrm{O}$ valor funcional é aqui atribuído à própria bica e seu entorno. A Bica do Ipu representa o aspecto da natureza em torno da qual ocorrem as atividades humanas mais significativas na área de pesquisa, que são aquelas associadas ao turismo regional voltado para o lazer (escaladas, rapel, banhos de bica, piqueniques, recreação familiar, alimentação, contato com a natureza). Com efeito, cerca de 5.000 pessoas visitam anualmente a bica, para realizar uma dessas atividades de recreação e lazer, segundo dados da gerência da APA.

A área de proteção ambiental da Bica do Ipu apresenta um valor educativo e científico significativo, resultante de pesquisas que evidenciaram a existência de elementos raros da fauna e geologia. É o caso da presença de caranguejos de águas doces. O crustáceo encontrado é da espécie Fredius Reflexifrons, típico da bacia amazônica, e foi descoberto pelos pesquisadores nos municípios de Ipu e Viçosa do Ceará. Segundo o Portal Nossa Ciência, a pesquisa de doutorado do biólogo Livanio Cruz dos Santos, intitulada "Caranguejo Relictual da Serra da Ibiapaba: o que nos diz a teoria dos refúgios?" Visa explicar a ocorrência dessa espécie no município de Ipu. Até o momento, foram mapeados quinze pontos com a ocorrência do crustáceo. A pesquisa quer apontar caminhos para a proteção da espécie, tida como relictual.

$\mathrm{Na}$ APA, foi identificado outro importante valor científico, de caráter paleontológico: no lugar também ocorrem anêmonas fossilizadas, de acordo com a pesquisadora da Universidade Estadual Vale do Acaraú- UVA, Professora Maria Somália Sales Viana:

A preservação desses fósseis é incomum, pois em geral corpos moles não são preservados em ambientes com grãos grossos, porém o rápido soterramento, que também causou a morte da biota, evitou a decomposição e a exposição a agentes externos. Além disso, há poucas ocorrências desses fósseis no mundo, sendo a primeira no Brasil e no período Siluriano, uma vez que essa biota viveu entre 436 a 443 milhões de anos, na Era Paleozoica. (www.uvanet.br)

\subsection{Problemas ambientais}

Na Área de Proteção Ambiental da Bica do Ipu, segundo a gerência da APA, cerca de 90\% das áreas nas quais estão inseridos os recursos hídricos, são de propriedade particular. Nos trabalhos de campo, foi possível verificar os grandes impactos causados pelos proprietários, tais como a construção de casas de veraneios e hotéis sem as devidas licenças ambientais e de poços profundos para fabricação de água engarrafada, além da degradação causada pelo uso do fogo para a agricultura, a qual provoca em determinados períodos do ano vários focos de incêndios florestais. A 
falta de coleta de lixo regular também é um fator de grande impacto, que gera sujeira no entorno da comunidade.

Ocorrem também atividades de mineração, tais como extração de rochas ornamentais, rochas para cantaria, brita, placas para fachadas e usos diversos na construção civil, ainda que de forma incipiente. Por outro lado, a extração de areia e argila (utilizada na fabricação de telhas e tijolos), bem como a extração de rocha calcária (utilizada na fabricação de cal) encontram-se difundidas no âmbito do município.

A população do entorno da área de proteção ambiental ainda não é sensível em relação à importância da geodiversidade e do patrimônio geológico de sua região serrana. Parcela desses moradores realizam pequenos barramentos no canal do rio utilizando sacos de areia e bananeiras para desvio de água para suas propriedades e fazem descarte irregular de agrotóxico, dentre outras atividades como queimadas e desmatamento irregulares, as quais geram impactos ambientais que atingem direta ou indiretamente a dinâmica das águas do riacho e da Bica do Ipu e a geodiversidade do lugar.

Monocultura de frutas (banana e abacate) e hortaliças é realizada através de modelos convencionais de agricultura, resultando em impactos negativos, tais como desmatamento, uso de defensivos químicos, degradação do solo e poluição dos recursos hídricos, gerando perda da biodiversidade. (Ziegler et al., 2013).

A riqueza natural da APA da Bica do Ipu é das mais expressivas. No entanto, verifica-se a necessidade de desenvolver projetos educativos voltados para a disseminação dos valores patrimoniais da geodiversidade e geoconservação junto com a população, com o objetivo de ampliar a sua conservação. Autores como Brilha, (2005); Carcavilla et al., (2007); Carcavilla (2012), dentre outros, apontam ferramentas para a promoção de estratégias de geoconservação. É necessário na APA a implantação de um modelo de gestão do meio natural que privilegie uma maior aproximação da população com o patrimônio geológico e geomorfológico, e a formação de uma sensibilidade sobre a importância da geodiversidade junto às atuais e futuras gerações.

As políticas de criação de unidades de conservação são positivas para os objetivos de conservar o patrimônio natural e para proteger amostras representativas dos ecossistemas naturais do Brasil. Com efeito, delimitam espaços destinados a preservar ou manejar ecossistemas para os mais variados objetivos de proteção ambiental. Essa política é reconhecida hoje em escala global.

No entanto, sabemos que, durante séculos, a ocupação das Américas e do Brasil em particular era formada pela necessidade de abrir territórios e o desflorestamento era o pressuposto da prova de ocupação, gerando direitos em favor do ocupante. Como exemplo temos a lei de terras 
do império, Lei $\mathrm{N}^{\circ} 601$, de 1850 , em que a posse era demonstrada com a morada habitual e cultivo dos terrenos, conceito que até hoje permanece relevante na nossa legislação.

Nas três últimas décadas do Século XX, a legislação ambiental como hoje a conhecemos começou a tomar corpo. Entretanto, o direito à propriedade imobiliária não se transformou com a mesma velocidade do conteúdo do direito ambiental, gerando conflitos na gestão dos espaços preservados por lei, especialmente os de uso sustentável, segundo definido pela lei.

Com efeito, legalmente, as categorias de Unidades de Conservação são divididas em dois grupos com características específicas, a Unidade de Proteção Integral e a Unidade de Uso Sustentável.

O objetivo básico das Unidades de Uso Sustentável é compatibilizar a conservação da natureza com o uso sustentável de parcela dos seus recursos naturais. Dentre elas se situa a Área de Proteção Ambiental. De acordo com o Artigo $7^{\circ}$ do SNUC, Área de Proteção Ambiental é uma área em geral extensa, com um certo grau de ocupação humana, dotada de atributos abióticos, bióticos, estéticos ou culturais especialmente importante para a qualidade de vida e bem-estar das populações humanas, e tem como objetivo básico proteger a diversidade biológica, disciplinar o processo de ocupação e assegurar a sustentabilidade do uso dos recursos naturais. No inciso $1^{\circ}$ essa lei destaca que: A Área de Proteção Ambiental é constituída por terras públicas e privadas.

A lei também explicita também que o objetivo das Unidades de Proteção Integral é preservar a natureza, sendo admitido apenas o uso indireto dos seus recursos naturais, com exceção dos casos previstos nesta Lei.

O SNUC, já com 15 anos de existência, não conseguiu a superação das dificuldades na gestão dos territórios das UCs, criadas em decorrência do pouco envolvimento da população na gestão das unidades de conservação. Diante desse cenário, a gerência da APA e seus conselheiros lutam para transformar a área em uma unidade de conservação integral, visando garantir uma maior proteção do ambiente e melhoria da fiscalização por parte dos órgãos responsáveis. A APA do Ipu provavelmente deveria ser incluída nessa tipologia, para permitir a real preservação do seu meio ambiente.

\section{CONSIDERAÇÕES FINAIS}

O presente trabalho apresenta uma contribuição para a compreensão da geodiversidade e geoconservação da APA da Bica do Ipu. A proposta de realização de pesquisa sobre a área levou em consideração processos e valores da geodiversidade, visando suprir a carência de estudos acerca da realidade geográfica da região. 
A análise do balanço entre os valores e as ameaças à geodiversidade na APA da Bica do Ipu, no município de Ipu-CE, justifica a necessidade de implementação de estratégias adequadas de gestão e conservação ambiental. Essas estratégias devem incluir obrigatoriamente atividades de educação ambiental, visando uma maior participação dos habitantes na preservação do ambiente que lhes diz respeito. Não se pode deixar de considerar também que há ausência de fiscalização e penalização adequada para os infratores da legislação ambiental existente nos limites da APA, o que amplia os problemas de degradação.

\section{REFERÊNCIAS}

ALENCAR, J. de. Iracema. São Paulo: Saraiva, 1956.

ARRUDA, K. E. C.; BARRETO, A. M. F. Índice De Geodiversidade do Município de Araripina PE, Brasil. Revista Estudos Geológicos, Pernambuco, v. 25(1), 2015.

BRASIL. Lei $N^{\circ}$ 601, de 18 de setembro de 1850. Dispõe sobre as terras devolutas do Império. Secretaria de Estado dos Negócios do Império, 2 out. 1850. Disponível em: Acesso em: 19 mar. 2018.

BRILHA, J. Patrimônio geológico e geoconservação: a conservação da natureza na sua vertente geológica. Braga: Palimage Editores, 2005. 190p.

BRITO NEVES, B. B. A história dos continentes - trajetórias e tramas tectônicas. In: MANTESSO-NETO, V. et al. (Org). Geologia do continente sul-americano: evolução da obra de Fernando Flávio Marques de Almeida, p. 123-149. São Paulo: Beca, 2004. Apud. MOURA-FÉ, M. M. (2015). Evolução geomorfológica da Ibiapaba setentronial, Ceará: gênese, modelagem e conservação. Tese de doutorado, Departamento de Geografia da UFC.

BRITO NEVES, B.B. Evolução cristal neoproterozoica da América do Sul. Recife: XXIII Simpósio de Geologia do Nordeste, pp. 78-84, 2009.

CARCAVILLA, U., L; LOPES-MARTINEZ, J.; DURAN VALSERO J.J. Patrimonio geológico y geodiversidade: investigación, conservación, gestión y relación los espacios naturales protegidos. Madrid: Instituto Geológico y Minero de España, 2007. 360p.

CARCAVILLA URQUI, L. Geoconservacion. Madrid: Editora Los libros de la Catarana, 2012. $128 \mathrm{p}$.

CEARÁ. IPLANCE. Atlas do Ceará. Fortaleza, 1997. Mapa colorido, Escala 1:1.500.000.

CEARÁ. Secretaria dos Recursos Hídricos (SRH). Plano Estadual de Recursos Hídricos: Atlas. Fortaleza, 1992, 4v, v.1.

CLAUDINO-SALES, V. Megageomorfologia do Estado do Ceará. História da Paisagem Geomorfológica, São Paulo: Nova Edições Acadêmicas, 2016. 59p. 
CPRM- Serviços Geológicos do Brasil. Mapa da Geodiversidade do Estado do Ceará. Escala 1:750.000. Fortaleza: CPRM, 2011.

. Projeto Cadastro de Fonte de Abastecimento por Água Subterrânea Diagnóstico do Município de Caicó. Org. Mascarenhas et al. Recife: CPRM/PRODEEM, 2005. Apud OLIVEIRA, F. R. de M. Geodiversidade No Município de Caicó: Uma Proposta de Roteiro Geoturístico. Caicó: UFRN, 2016. 48p. Disponível m: $<$ https://monografias.ufrn.br/jspui/bitstream/123456789/3450/3/Geodiversidade\%20no\%20munic\% C3\%ADpio\%20de\%20Caic\%C3\%B3_Monografia_Oliveira>. Acesso em: 12 jun. 2018.

. Mapa do perfil geológico. UFPA/CPRM, 2014.folha SB.24-

V-A-III IPU. Escala 1:100.000.

GRAY, M. 2004. Geodiversity. Chichester: John Wiley e Sons Ltd., 2004, 434p.

GUERRA, Texeira J.A ; CUNHA, Sandra Baptista da. (Orgs.). Geomorfologia do Brasil. 3. ed. Rio de Janeiro: Bertrand Brasil, 2003. 392p.

IBGE. Censo 2010 - Município de Ipu-CE. Disponível em: <https://cidades.ibge.gov.br/brasil/ce/ipu/panorama>. Acesso em: 23 mar. 2018.

LICCARDO, A.; PIEKARZ, G.; SALAMUNI, E. Geoturismo em Curitiba. Curitiba: MINEROPAR, 2008. 122p.

MELLO, M V. C. O Ipu em três épocas. Ipu: Popular Editora Ltda, 1985

MÖBUS, G. SILVA. C. M. S. V \& FEITOSA, F. C. Perfil estatístico de poços no cristalino Cearense. In: SIMPÓSIO DE HIDROGEOLOGIA DO NORDESTE, 3, 1998, Recife. Anais do... Recife: ABAS, 1998. p.184-192. Apud. BENVENUTI, S. M. P. e FEITOSA, F. A. C. (Org.) Diagnóstico Do Município De Tianguá. Fortaleza: Ministério de Minas e Energia; CPRM. 1998. $16 \mathrm{p}$.

OLIVEIRA, J. B. et al. Classes gerais de solos do Brasil: guia auxiliar para seu reconhecimento. Jaboticabal, 1992. 201p.

Portal Nossa Ciência. Caranguejo amazônico no Ceará. Disponível em:<http://nossaciencia.com.br/colunas/caranguejo-amazonico-no-ceara>. Acesso em:18 mar. 2018.

RESENDE, M. et al. Pedologia: base para distinção de ambientes. Viçosa: NEPUT, 1995. 304p.

SHARPLES, C. Concepts and Principles of Geoconservacion. Documento em PDF disponibilizado na Tasmanian Parks \&Wildlife Service website, 2002. Disponível em: <http://www.parks.tas.gov.au/geo/conprin/define.html>. Acesso em: 10 abr. 2015. Apud. NASCIMENTO, M. A. L. do. et al. Bases Conceituais para entender Geodiversidade, Patrimônio Geológico, Geoconservação e Geoturismo. In: XVI Simpósio Brasileiro de Geografia Física. Revista Equador, Piauí, v.4, n.3, ed. especial 2. 2015. p.

SILVA, C. R.(org). Geodiversidade do Brasil: conhecer o passado, para entender o presente e prever o futuro. Rio de Janeiro: CPRM, 2014. 264p. 
SIQUEIRA Filho; ALVES, J. Flora das Caatingas do Rio São Francisco: história natural e conservação. Rio de Janeiro: Andrea Jakobsson, 2012. 446-542p.

Superintendência Estadual do Meio Ambiente. Governo do Estado do Ceará. Área de proteção da Bica do Ipu. Disponível em: $<$ http://www.semace.ce.gov.br/2010/12/area-de-protecao-ambientalda-bica-do-ipu/>. Acesso em: 2 fev. 2018.

Universidade Estadual Vale do Acaraú. Notícias - Pesquisa desenvolvida na UVA e UFPE sobre fósseis marinhos do semiárido cearense é apresentada em Congresso Internacional de Paleontologia. Disponível em: <http://www.uvanet.br/noticias_mostra.php?id=1573>. Acesso em: 1 fev. 2018.

VIEIRA, L. S. Manual de ciência do solo: com ênfase aos solos tropicais. São Paulo: Agronômicas, 1988. 464p.

ZIELGLER, H. R.S. et al. A busca pelo desenvolvimento rural sustentável na área de Proteção Ambiental- APA da Bica do Ipu-Ceará. Cadernos de Agroecologia, v.8, n.2, nov. 2013, 1-5p.

\section{AGRADECIMENTOS}

Primeiramente a Deus, pela luz divina, à FUNCAP pela concessão da bolsa para qualificar minha pesquisa, a minha filha, Clara Vitória, minha lua! E ao meu companheiro Davi, com quem sempre partilhei ideias, conquistas e dificuldades nos últimos anos da minha vida.

Recebido em: 11/08/2019

Aceito para publicação em: 24/09/2019 